next two decades, the divergence of interests will create political conflict among institutions. It seems inevitable that some of the institutions will have to be closed down or merged with others.

The Korean government decided to move away from strict regulations to more market-based policies. Despite this change in direction, the government's role in higher education will not diminish at all, as it is imperative that the government maintains and enforces the rules of the game used in the competition. Since Korean higher education relies heavily on the private sector, the sector's effort of imposing market principles of transparency and openness would be useful in evaluating whether these policies create accountability and other desirable outcomes.

\section{Academic Integrity and Its Limits in Kyrgyzstan}

\section{Madeleine Reeves}

Madeleine Reeves is a doctoral candidate in social anthropology at the University of Cambridge. She is currently research associate at the East-West Center for Intercultural Dialogue at the American University-Central Asia in Bishkek, Kyrgyzstan. Address: Trinity College, Trinity Street, Cambridge CB2 1TQ, UK. E-mail:mfr21@cam.ac.uk.

A recent issue of International Higher Education sought to draw attention to the question of corruption in academe, a topic that has tended to be politely passed over in analyses of higher education policy and practice (see IHR no. 34). When it is discussed, corruption is generally portrayed as a deviation from some presumed "normal" state of affairs: it is portrayed as the exception, rather than the rule-the fault of the miscreant teacher, the lazy student, or the immoral administrator, rather than the product of systemic difficulties. The very language we invoke tends to presume the corruptness of a basically sound system, rather than a fundamental mismatch between what individuals and institutions are nominally "supposed" to provide and their ability to do so in practice.

This article proposes a somewhat different framework for thinking about the possibilities for ethically sound educational practice. It asks about the preconditions for, and limits to, academic integrity, the latter term understood in its double definitions of "moral uprightness, honesty" and "wholeness, soundness." Corruption, in this perspective, is interpreted not as the deviant action of particular immoral individuals, but the symptom of a much broader, systemic dis-integration: the inability of certain parts of a system to integrate with, and thus respond to the needs of, other parts. This article draws upon interviews with academics and students in
Kyrgyzstan over three years, as well as the author's direct participant observation as a teacher of English in a remote, regional state university in which instances of corruption are widespread.

\section{Kyrgyzstan, as many other post-Soviet edu- cational systems, retains a high degree of ministerial control over the content and structure of university curricula.}

\section{Impositions and Improvisations}

Kyrgyzstan, as many other post-Soviet educational systems, retains a high degree of ministerial control over the content and structure of university curricula. Ministerial plans dictate the precise number of hours that students of a given "speciality" are to dedicate to different subjects during the course of their five years of university education; these plans are typically displayed prominently in university corridors, and they regulate closely student and teacher course loads in any given term, the scope of particular disciplines, and the chronological order in which subjects are to be taught. A small percentage of courses can be nominated by faculty deans and departmental chairs (also subject to ministerial approval), and students are nominally entitled to one or two "optional courses" (kursy po vyboru) in their final years of study, although in practice these tend to be narrowly prescribed - often to a choice of just one. The standard teaching course load is 500 classroom hours per term, a figure that, week-by-week, would stagger many Western academics. Punishingly low rates of pay mean that it is not uncommon for teachers, especially younger teachers (who need more time for course preparation) to take on 1.5 and even double course loads in order to make ends meet.

Such a system presupposes both a considerable degree of homogeneity among student intakes across the population (students all entering university with an identical degree of preparation) and the ability of all universities to meet ministerial requirements in terms of personnel, literature, and material resources. Rural universities expose with particular clarity the absurdity of such assumptions. For while the university curricula in such institutions mirror those taught in the capital city, entering students come with nothing like the same degree of preparation, and the pool of qualified teachers that the institution is able to attract is far smaller.

The reality, of course, is that with all the goodwill in the world teachers simply cannot deliver what is expected of them. The result is either that they decide to deviate massively from the nominal content of a course 
in order to cover the basics or that they stick to the intended content, leaving the students floundering as they fail to grasp the meaning of the material presented. In either case, academic integrity is jeopardized, since the list of courses and grades that are accumulated in the grade book (zachetka) at the end of each term bear little correspondence with material taught or knowledge gained. What is true of the individual student's grades is true also of the department's register of lectures given, the dean's list of courses taught, the rector's reports on the institution's ability to meet its academic targets, and the ministry's announcements to the outside world about the impressively high levels of tertiary education in Kyrgyzstan. In each case, the rhetoric has little correspondence with the reality facing students and teachers.

The reality, of course, is that with all the goodwill in the world teachers simply cannot deliver what is expected of them.

\section{Dis-integration and Corruption}

Such a lack of correspondence leaves the door wide open for corruption. Obviously, teachers are far more likely to seek bribes, and students are far more likely to give them when it is nearly impossible to answer exam questions honestly for want of coverage of the relevant material. More insidiously, the constant-indeed institutionalized-lack of correspondence between what is claimed and what is delivered (and what can, in fact, be delivered), between the actual and the "certified," blurs the boundary between ethical and unethical. Acting "ethically" in academe becomes divorced from the idea of testing ability according to firm, transparent, and nonnegotiable standards of knowledge gained. With so much improvisation required by the system (the paradoxical consequence of ministerial overcontrol), the grade book is no longer an index of "knowledge gained" but instead a statement of a personalized relationship between teacher and student. This transformed relationship is only reinforced by a system of government grants for higher education that penalizes students financially for a single grade below a " 4 " (corresponding roughly to a "B" in the U.S. system) and by the chronic underfunding of higher education, which means that feepaying students (kontraktniki) will virtually never be excluded from a university for poor academic performance if they continue to pay their bills. In such a context, institutions often consider it perfectly "ethical" for a teacher to give a high grade to an academically undeserving but financially needy student studying at uni- versity on a government stipend. The motivation is to ensure that the student concerned retains the grant that supports her family or to lower the academic requirements for the kontraktniki who are paying for their degrees-to keep the enrollments up for a given program and to keep money flowing into the university coffers.

These practices may not be instances of corruption per se, but they certainly damage the academic integrity of the institution and represent a violation of the ethical obligations that exist between teacher and student and between university and the wider society. They also open the door to other, more egregious forms of corruption that are widespread in Kyrgyzstan: bribes to teachers for end-of-term grades and bribes by teachers for academic positions; the purchasing of course papers, senior theses (diplomnaya rabota), and even candidate of science degrees; and payments and favors to admissions committees, departmental chairs, and examination commissions.

The result is not only the production of underqualified specialists whose real knowledge corresponds only remotely with the list of courses detailed on their diplomas. Another effect is a much more profound societal scepticism regarding assertions of educational expertise. As the title of a recent newspaper article on the issue put it, "the red diploma is fading" in contemporary Kyrgyzstan. What was formerly an indicator of academic excellence, awarded only if one had the highest grade in all subjects, has been devalued into a near meaningless currency.

"How do we stop students from giving bribes, and teachers from taking them?"

To deal with the problem of corruption in higher education, therefore, it is not enough simply to ask, as is typically done in Kyrgyzstani public discourse, "how do we stop students from giving bribes, and teachers from taking them?" We must ask the much broader questions, "how do we re-integrate the system?" "What are the institutional and administrative preconditions for academic integrity?" "How can we reinstate a boundary between ethical and unethical in a way that meets rigorous academic criteria?" To address these questions, it is not enough only to pay teachers more (although that is crucial since academic integrity is impossible when teachers cannot earn a living wage), nor is it sufficient simply to expose instances of bribe giving and taking within a given institution.

Answering these questions demands, more radically, that we think structurally and systematically about the 
relationship between the Ministry of Education, particular institutions, the student body, and the wider public. Greater autonomy is required to determine curricular content for faculties and individual departments. Basing the allocation of funding for university programs on individual student grades needs to be ended since it can lead to grade inflation. A substantial cut is needed in the number of courses that students are expected to take and teachers are expected to teach, which leaves little time for assimilating and preparing material, and encourages a "memorize-reciteforget" approach to learning. Perhaps most importantly, it demands that curricula and individual courses at all universities, especially those catering to a predominantly rural student body, be configured to meet the needs of today's school leavers, taking into consideration actual rather than imagined levels of preparation and available rather than hypothetical course materials.

\section{Higher Education in Kazakhstan: The Issue of Corruption}

\section{Nataliya L. Rumyantseva}

Nataliya Rumyantseva is a doctoral student in higher education administration, in the Department of Leadership, Policy and Organization, Peabody College at Vanderbilt University. Address: Vanderbilt University, 230 Appleton Place, Box 520, Nashville TN 37203, USA. E-mail: n.rumyantseva@vanderbilt.edu.

A ccording to multiple reports from students, corruption has hampered higher education systems in the post-Soviet region. Faculty members charge students for exam grades; administrators charge for admissions. Anecdotal evidence suggests that academic corruption may be a pervasive phenomenon in higher education in the region.

Higher education in Kazakhstan provides an illustration of corruption in the sector. According to a 2002 World Bank survey, higher education in Kazakhstan is perceived as corrupt by the public. One out of four surveyed households that had a student at a university reported paying a bribe for higher education services. Seventy-four percent of reported bribes were made to a specific person associated with a university. When asked about why they paid a bribe, 69 percent of respondents said they did it to obtain admission to a university and 10 percent to receive better grades.

The existence of corruption inhibits the ability of educational systems to serve the economy and society. It misleads employers and evokes mistrust among the general public. Corruption depraves civic culture by generating the impression that universities are unfair to young people, while breeding a culture of cynicism about the nation and its claimed civic virtues. When higher education is corrupt, young people come to believe that cheating and bribing may advance their careers.

Despite the possible pervasive and serious consequences, educational corruption has only recently drawn some attention in higher education literature. The current discussion of educational corruption is largely supported by anecdotal evidence. This article is based on a survey and interviews with students in the Republic of Kazakhstan in spring 2003 on their personal experience with and perception of corruption.

Two survey instruments were administered to 1,000 university students and 250 faculty members at a large state university in Kazakhstan with about 10,000 students and 900 faculty. To ensure reliable responses, respondents were guaranteed anonymity and confidentiality. Additionally, interviews were conducted with top university administrators, to obtain their views on corruption at their institution.

\section{The findings of the survey support the claim that corruption in higher education exists.}

\section{Evidence of Corruption}

The findings of the survey support the claim that corruption in higher education exists. Although few students (10 percent) and faculty members (6 percent) explicitly admit personal involvement in educational corruption, the vast majority (88 percent of faculty and 74 percent of students) agree with the statement that corruption in higher education is a widespread occurrence. Areas perceived as most corrupt are admissions and exams. Some 78 percent of students and 62 percent of faculty report that corruption most frequently occurs during examination sessions. Seventeen percent of students and 28 percent of faculty in the sample consider admissions the most corrupt area in higher education. The interviews of administration officials revealed that they are rather reluctant to acknowledge the issue and choose to deny it, at least to the external observer.

\section{Control Mechanisms}

The state of formal control mechanisms that explicitly regulate corruption appears to be weak. About 80 percent of faculty members report that they have never read rules explicitly regulating activities such as charging students or accepting gifts or services for grades. Similarly, about 90 percent of students report they never read any rules that explicitly regulate faculty-student exchange of money, gifts, or services for grades. University offi- 